\title{
Randomised crossover trial of salbutamol aerosol delivered by metered dose inhaler, jet nebuliser, and ultrasonic nebuliser in chronic lung disease
}

\author{
T F Fok, K Lam, P C Ng, H K So, K L Cheung, W Wong, K W So
}

\begin{abstract}
Aims-To compare the efficacy of salbutamol delivered by metered dose inhaler (MDI), jet nebuliser, and ultrasonic nebuliser in ventilated infants with chronic lung disease.

Methods-Twenty preterm ventilated infants with chronic lung disease were enrolled in two studies. In study $1(n=10)$, each infant was given $200 \mu \mathrm{g}$ of salbutamol at 4 hour intervals and in random sequence from a metered dose inhalerspacer device, a jet nebuliser, and an ultrasonic nebuliser with a small medication cup. The infants were monitored for heart rate, transcutaneous $\mathbf{p O}_{2}, \mathbf{p C O}_{2}$, and oxygen saturation, respiratory system resistance and compliance before and after each treatment. Infants in study 2 $(n=10)$ were similarly studied except for the use of a different jet nebuliser.

Results-The mean (SEM) maximum percentage decreases in respiratory system resistance, observed at 30 minutes after aerosol delivery were study 1: MDI: 44.3 (4.3)\% ; jet: 32.3 (3.4)\% ; ultrasonic: 56.1 (3.2)\% ; study 2: MDI: $28.6(1.0) \%$; jet: 16.9 (1.4)\% ; ultrasonic: 42.1 (1.6)\%. During the first hour after treatment, a significantly faster heart rate and higher transcutaneous $\mathrm{pO}_{2}$ were associated with the use of the ultrasonic nebuliser or MDI than with the jet nebulisers in both studies. The use of the ultrasonic nebuliser but not the other devices also resulted in a lower transcutaneous $\mathrm{pCO}_{2}$ and improved respiratory system compliance in study 2 .

Conclusions-These findings suggest that among the devices tested, the delivery of salbutamol aerosol to the lower respiratory tract was greatest using the ultrasonic nebuliser, and least with the jet nebulisers. (Arch Dis Child Fetal Neonatal Ed 1998;79:F100-F104)
\end{abstract}

Paediatrics, Th Chinese University of

Hong Kong, The

Prince of Wales

Hospital, Shatin, Hong

Kong, People's

Republic of China

T F Fok

K Lam

$\mathrm{PC} \mathrm{Ng}$

$\mathrm{H}$ K So

K L Cheung

W Wong

KW So

Correspondence to:

Dr T F Fok.

Accepted 4 February 1998 ronchodilator aerosols are useful in relie bronchiolar constriction in infants requiring mechanical ventilation for bronchopulmonary dysplasia. (BPD). ${ }^{1-7}$ The medication can be delivered by a metered dose inhaler (MDI), jet nebuliser, or an ultrasonic nebuliser. The MDI and the jet nebuliser are currently the most commonly used devices, but earlier studies in human, animal, and filter lung models have shown that pulmonary deposition of aerosol by these devices is small, being 0.2 to $2 \%$ of the nominal dose used. ${ }^{8-17}$ In two recent studies comparing the delivery of salbutamol to infants with chronic lung disease, using the MDI and jet nebuliser, the MDI was able to deposit more aerosol in the infants' lungs, ${ }^{10}$ and bring about greater improvement in dynamic lung mechanics. ${ }^{18}$ The ultrasonic nebuliser has been evaluated in neonates and small infants in two earlier studies, both showing relatively small lung deposition, ${ }^{913}$ but recent evidence from both adult and animal neonatal lung models shows that the device achieves significantly greater pulmonary deposition than the MDI or jet nebuliser. ${ }^{19}{ }^{20}$ However, as far as we are aware there has been no direct comparison of the three types of devices on human infants.

We undertook two double blind, randomised crossover studies to compare the three types of devices in mechanically ventilated infants with chronic lung disease. The pharmacological effects of a standard dose of salbutamol were used as the outcome measures. The same MDI-spacer device and ultrasonic nebuliser, but two different models of jet nebuliser, were used in the two studies. The design was intended to improve the applicability of the findings as several jet nebulisers of variable performance are available in the market.

\section{Methods}

The studies were approved by the Ethics Committee of the Chinese University of Hong Kong. Twenty preterm infants diagnosed consecutively to have BPD or to be at risk of developing it were enrolled after informed parental consent had been obtained if they satisfied the following criteria: (i) gestation < 32 weeks; (ii) birthweight $<1.5 \mathrm{~kg}$; (iii) postnatal age $\geq 2$ weeks; (iv) requirement for mechanical ventilation to treat respiratory distress syndrome for at least three days during the first week of life; (v) ventilator and oxygen dependent at the time of enrolment; (vi) chest radiograph showing changes consistent with chronic lung disease ${ }^{21}$; and (vii) ventilation and oxygen requirements being stable for at least 24 hours. Infants with anatomical abnormalities of the airway were excluded.

The first 10 infants enrolled (study 1 ) were 
Table 1 Demographic characteristics of infants studied

\begin{tabular}{lll}
\hline & Mean (SEM) & Range \\
\hline Study 1: & & \\
Gestation (weeks) & $26.3(0.9)$ & $24.3-32.0$ \\
Birthweight (g) & $861(99)$ & $653-1490$ \\
Postnatal age (days) & $39.2(11.7)$ & $14-141$ \\
Body weight at study (g) & $1301(225)$ & $700-3095$ \\
Peak inspiratory pressure (cm & & \\
$\left.\quad \mathrm{H}_{2} \mathrm{O}\right)$ & $17.3(0.6)$ & $14-21$ \\
Ventilator rate (breaths/min) & $9.9(1.2)$ & $5-16$ \\
$\mathrm{FIO}_{2}$ & $0.31(0.01)$ & $0.26-0.37$ \\
Study 2: & & \\
Gestation (weeks) $_{\text {Birthweight (g) }}$ & $26.9(0.9)$ & $24.3-30.5$ \\
Postnatal age (days) $_{\text {Body weight at study (g) }}$ & $624(83)$ & $545-1390$ \\
Peak inspiratory pressure (cm & $1667(123)$ & $30-100$ \\
$\left.\quad \mathrm{H}_{2} \mathrm{O}\right)$ & $17.5(0.6)$ & $15-2000$ \\
Ventilator rate(breaths/min) & $95(1.5)$ & $5-20$ \\
FIO $_{2}$ & $0.27(0.01)$ & $0.24-0.30$ \\
\hline
\end{tabular}

comparison was made using the same MDIspacer device and ultrasonic nebuliser but a different jet nebuliser (Flo Thru, Hudson RCI, USA).

AEROSOL DELIVERY

In both studies each infant was given one dose of salbutamol aerosol (200 $\mu$ g per dose) from each of the three devices at 4 hourly intervals and in random sequence. Allocation was carried out using computer generated random numbers. The aerosol was delivered by one investigator not involved in the clinical management of the infants. Another investigator, who was not present during aerosol delivery and blinded to the type of device used, was responsible for data collection and lung

Table 2 Heart rate, spontaneous respiratory rate, $\mathrm{SaO}_{2}, t c \mathrm{PO}_{2}$ and tcPCO $\mathrm{P}_{2}$ immediately before salbutamol treatment: mean (SEM)

\begin{tabular}{llllll}
\hline Device used & $\begin{array}{l}\text { Heart rate (beats } \\
\text { per min) }\end{array}$ & $\begin{array}{l}\text { Respiratory rate } \\
\text { (breaths per min) }\end{array}$ & $\mathrm{SaO}_{2}(\%)$ & $\begin{array}{l}\mathrm{tcPO}_{2}(\mathrm{~mm} \\
\mathrm{Hg})\end{array}$ & $\begin{array}{l}\mathrm{tcPCO} \\
(\mathrm{mm} \mathrm{Hg})\end{array}$ \\
\hline $\begin{array}{l}\text { Study 1: } \\
\text { 1 (MDI) }\end{array}$ & $139.7(4.1)$ & $42.3(4.1)$ & $94.3(1.2)$ & $62.9(3.5)$ & $33.5(1.3)$ \\
2 (Jet) & $138.5(4.0)$ & $40.5(1.4)$ & $94.4(1.0)$ & $62.1(3.1)$ & $33.4(1.6)$ \\
3 (Ultrasonic) & $139.7(3.9)$ & $41.0(1.2)$ & $95.6(1.2)$ & $62.5(3.5)$ & $34.0(1.4)$ \\
$\mathrm{p}^{\star}$ & 0.784 & 0.811 & 0.655 & 0.886 & 0.887 \\
Study 2: & & & & & \\
1 (MDI) & $142.0(4.1)$ & $400(1.8)$ & $93.0(1.0)$ & $62.2(2.5)$ & $32.6(1.0)$ \\
2 (Jet) & $139.3(3.4)$ & $39.7(1.8)$ & $94.5(1.1)$ & $62.1(2.2)$ & $32.7(1.0)$ \\
3 (Ultrasonic) & $141.8(3.5)$ & $38.2(2.1)$ & $94.2(1.1)$ & $61.7(2.3)$ & $34.3(0.8)$ \\
$\mathrm{p}^{\star}$ & 0.689 & 0.497 & 0.645 & 0.908 & 0.298 \\
\hline
\end{tabular}

${ }^{\star}$ One way repeated measures ANOVA.

Table 3 Heart rate, spontaneous respiratory rate, $\mathrm{SaO}, t c \mathrm{PO}_{2}$ and $t c \mathrm{PCO}_{2}$ within first 60 minutes after delivery of salbutamol aerosol

\begin{tabular}{|c|c|c|c|c|c|}
\hline \multirow[b]{2}{*}{ Device used } & \multicolumn{5}{|c|}{ Area under the curve/60 min: adjusted mean (SEM) } \\
\hline & $\begin{array}{l}\text { Heart rate } \\
\text { (beats/min) }\end{array}$ & $\begin{array}{l}\text { Respiratory rate } \\
\text { (breaths/min) }\end{array}$ & $\mathrm{SaO}_{2}(\%)$ & $\begin{array}{l}{ }_{t c P \mathrm{O}_{2}} \\
(\mathrm{~mm} \mathrm{Hg})\end{array}$ & $\begin{array}{l}t c P C O_{2} \\
(m m ~ H g)\end{array}$ \\
\hline \multicolumn{6}{|l|}{ Study 1: } \\
\hline 1 (MDI) & $168.6(3.6)$ & $43.9(1.2)$ & $95.9(0.6)$ & $64.1(0.8)$ & $32.2(0.8)$ \\
\hline 2 (Jet) & $155.7(3.6)$ & $42.7(1.2)$ & $96.7(0.6)$ & $61.3(0.8)$ & $32.2(0.8)$ \\
\hline 3 (Ultrasonic) & $168.8(3.6)$ & $42.1(1.2)$ & $95.8(06)$ & $67.7(0.8)$ & $30.6(0.8)$ \\
\hline$F$ test $p^{\star}$ & $0.023^{1}$ & 0.574 & 0.461 & $0.0001^{2}$ & 0.330 \\
\hline \multicolumn{6}{|l|}{ Study 2: } \\
\hline 1 (MDI) & $156.7(1.3)$ & $43.0(1.2)$ & $94.8(0.3)$ & $64.5(0.5)$ & $30.4(0.7)$ \\
\hline 2 (Jet) & $151.6(1.9)$ & $41.0(1.2)$ & $95.3(0.3)$ & $62.3(0.5)$ & $31.9(0.7)$ \\
\hline 3 (Ultrasonic) & $168.8(1.3)$ & $430(1.2)$ & $954(0.3)$ & $64.7(0.5)$ & $28.7(0.7)$ \\
\hline$F$ test $p^{\star}$ & $0.0001^{3}$ & 0.226 & 0.477 & $0.006^{4}$ & $0.014^{5}$ \\
\hline
\end{tabular}

TAdjusted by covariance analysis with the pre-treatment values as covariance.

*Analysis of covariance.

Multiple pairwise comparison by pairwise student $t$ test (adjusted for number of comparison):

1 MDI vs jet: $\mathrm{p}=0.018$; Jet $v$ ultrasonic: $\mathrm{p}=0.016$.

2 MDI vs jet: $\mathrm{p}=0.022 ; \mathrm{MDI}$ vs ultrasonic: $\mathrm{p}=0.003$; Jet $v$ ultrasonic: $\mathrm{p}=0.0001$

3 MDI vs jet: $\mathrm{p}=0.012$; $\mathrm{MDI}$ vs ultrasonic: $\mathrm{p}=0.024$; Jet $v$ ultrasonic: $\mathrm{p}=0.0001$.

4 MDI $v$ j jet: $\mathrm{p}=0.007$; Jet $v$ s ultrasonic: $\mathrm{p}=0.003$.

5 Jet $v s$ ultrasonic: $\mathrm{p}=0.004$. function measurement. Throughout the experiment, the $\mathrm{FIO}_{2}$ and ventilator settings were kept unchanged.

Immediately before delivery of the MDI salbutamol, a MV15s Aerochamber was inserted between the $\mathrm{Y}$ connector of the ventilator circuit and endotracheal tube. Two puffs of salbutamol MDI (100 $\mu \mathrm{g}$ per puff) were actuated into the spacer, one minute apart, at the end of the expiratory phase of a ventilator generated breath. The MDI canister was vigorously shaken for at least 10 seconds before each actuation. The spacer was removed one minute after the second puff.

The jet nebulisers and the ultrasonic nebuliser were connected to the inspiratory limb of the ventilator circuit $20 \mathrm{~cm}$ away from the endotracheal tube. Two hundred micrograms of salbutamol respirator solution (Ventolin, Glaxo UK) diluted with isotonic saline to a total volume of $4 \mathrm{ml}$ were added to the nebuliser reservoir. The jet nebulisers were operated by an external gas flow of 61 /minute, as recommended by the manufacturer. The ventilator flow rate was decreased accordingly during nebulisation so that the total flow rate through the circuit and the ventilator pressure remained unchanged. The reservoir used in the ultrasonic nebuliser was a small $(10 \mathrm{ml})$ disposable cone shaped medication cup with a tapered bottom and a volume equivalent to only half of that of the round bottom standard reservoir. The medication cup was placed inside the standard reservoir to which $10 \mathrm{ml}$ water had been added to act as a coupling fluid for the transmission of vibration energy. No adjustment of ventilator flow was required for the ultrasonic nebuliser as it does not involve any additional flow. With both types of nebulisers, nebulisation was continued till no aerosol was visibly generated.

\section{OUTCOME MEASURES}

The infants were monitored for their transcutaneous oxygen saturation $\left(\mathrm{SaO}_{2}\right)$ (Nellcor $\mathrm{N} 200 \mathrm{E}$ pulse oximeter, Nellcor Inc., CA, USA), transcutaneous $\mathrm{pO}_{2}\left(\mathrm{tcPO}_{2}\right)$, and $\mathrm{pCO}_{2}$ $(\text { tcpCO })_{2}$ ) (Hewlett Packard M1205A, Hewlett Packard Inc., USA) immediately before and for at least one hour after completion of aerosol delivery. Heart rate and respiratory rate were also monitored electronically. Spontaneous respiratory rate was obtained by subtracting the ventilator rate from the total respiratory rate registered by the monitor. The values of all the above parameters were recorded every minute except during lung function measurement. The areas under the curves plotting these values against time permitted comparison of these parameters following aerosol delivery by the three devices.

Static respiratory system compliance (Crs) and resistance (Rrs) were measured using the SensorMedics Pulmonary Cart (SensorMedics Inc., Yorba Linda, CA, USA) immediately before, and at 15, 30 minutes, 1 and 2 hours after completion of aerosol administration. All the measurements were carried out during quiet breathings. The parameters were measured using the passive flow-volume technique ${ }^{22}$ 
Table 4 Respiratory system compliance before and after salbutamol aerosol

\begin{tabular}{|c|c|c|c|c|c|c|}
\hline \multirow[b]{2}{*}{ Device used } & \multicolumn{6}{|c|}{ Respiratory system compliance ( $\left.\mathrm{ml} / \mathrm{cm} \mathrm{H}_{2} \mathrm{O} / \mathrm{kg}\right)$ : mean (SEM) } \\
\hline & Before & $15 \mathrm{~min}$ & $30 \mathrm{~min}$ & $60 \mathrm{~min}$ & $120 \mathrm{~min}$ & $p^{*}$ \\
\hline \multicolumn{7}{|l|}{ Study 1: } \\
\hline 1 (MDI) & $1.06(0.29)$ & $1.17(0$ & 1.1 & 1.22 & .36) & 0.199 \\
\hline 2 (Jet) & $0.98(0.30)$ & 1.02 & $1.07(0.35)$ & $1.07(0.34)$ & $1.06(0.37)$ & 0.527 \\
\hline 3 (Ultrasonic) & $0.96(0.32)$ & $1.11(0.33)$ & $1.15(0.37)$ & $1.11(0.33)$ & $1.07(0.34)$ & 0.174 \\
\hline \multicolumn{7}{|c|}{ Study 2: } \\
\hline 1 (MDI) & $0.84(0.13)$ & $0.81(0.13)$ & $0.88(0.15)$ & $0.88(0.15)$ & $0.85(0.13)$ & 0.087 \\
\hline 2 (Jet) & $0.84(0.13)$ & $0.87(0.14)$ & $0.87(0.13)$ & $0.88(0.13)$ & $0.83(0.12)$ & 0.203 \\
\hline 3 (Ultrasonic) & $0.84(0.13)$ & $0.90(0.13)$ & $0.95(0.14)$ & $0.92(0.13)$ & $0.89(0.13)$ & $<0.0001 \dagger$ \\
\hline
\end{tabular}

*One way repeated measures ANOVA.

†Pairwise comparison by Stedent-Newman-Keul method: before $<$ all the rest; $\mathrm{p}<0.05$.

which involves the occlusion of the airway at end inspiration to relax the respiratory muscles, by evoking the Hering-Breuer reflex. Release of the occlusion is followed by a passive exhalation required for the measurement of flow. The measurement was carried out using a pneumotachograph (Hans Rudolph Inc., USA) with a small dead space $(1.8 \mathrm{ml})$ connected to the endotracheal tube. The pneumotachograph contained a built-in pneumatically driven sliding valve used for airway occlusion, and a side port which was connected to a pressure transducer for the measurement of airway pressure. Flow signals were integrated to volume with a microcomputer. The flow-volume relation permitted the determination of the total passive expiratory volume $\left(\mathrm{V}_{\mathrm{E}}\right)$ at zero flow; and also the flow at zero volume $\left(\mathrm{V}_{0}\right)$ appropriate for the occlusion pressure $\left(\mathrm{P}_{\mathrm{ao}}\right)$. Crs and Rrs were calculated by the computer as follows: $\mathrm{Crs}=\mathrm{V}_{\mathrm{E}}$ $/ \mathrm{P}_{\mathrm{ao}} ; \operatorname{Rrs}=\mathrm{P}_{\mathrm{ao}} / \mathrm{V}_{0}$. A breath was accepted for analysis only when the occlusion pressure reached a stable plateau. In each measurement Crs and Rrs were obtained from the mean values of at least 10 acceptable breaths with a coefficient of variation of less than $10 \%$.

STATISTICS

All values are expressed as mean (SEM). One way repeated measures analysis of variance (ANOVA) was used for the comparison of repeated measurements in the same infants. Comparisons among multiple groups were made using one way ANOVA. With both methods, the presence of a significant difference was followed by multiple pairwise comparison using the pairwise Student $t$ test or the Student-Newman-Keul method. For comparison of post treatment heart rate, respiratory rate, $\mathrm{SaO}_{2}, \mathrm{tcpO} 2$, and tcpCO2, the areas under the curves are first adjusted for the pretreatment values by covariate analysis, and then divided by the baseline interval ( 60 minutes).

\section{Results}

The demographic characteristics of the study infants are summarised in table 1 . In both studies the time required by the nebulisers to aerosolise completely their contents was about 13 minutes for the ultrasonic nebuliser and 15 minutes for the jet nebulisers.

Table 2 shows the baseline heart rate, spontaneous respiratory rate, $\mathrm{SaO}_{2}, \mathrm{tcpO}_{2}$ and tcp $\mathrm{CO}_{2}$ of the infants. There were no significant differences in these parameters before aerosol delivery by each of the devices in either of the studies. All infants developed clinically significant tachycardia after salbutamol treatment delivered by all three types of devices. Maximum heart rate reached 200 per minute. Table 3 gives the areas under the curves, plotting the above parameters against time. Compared with the jet nebulisers, both the ultrasonic nebuliser and the MDI were associated with a faster heart rate and a higher tcpO $\mathrm{O}_{2}$ in both studies. In study 2 a significantly lower tcpCO $\mathrm{CO}_{2}$ was observed after treatment with the ultrasonic nebuliser than with the jet nebuliser.

Table 4 shows the Crs of the infants before and after salbutamol treatment. In study 1 delivery of the bronchodilator by all three delivery devices did not result in any significant change in Crs. In study 2 a significant increase in Crs was observed 30 and 60 minutes after aerosol delivery by the ultrasonic nebuliser. In contrast, the use of the MDI or jet nebuliser was not associated with any significant change in Crs after aerosol treatment.

The changes in Rrs are given in table 5. In both studies, and with all three types of delivery devices, administration of salbutamol aerosol was followed by a significant decrease in Rrs. The maximum improvement was observed at 30 minutes, after which Rrs gradually returned to the pre-treatment values. The maximum percentage decrease in Rrs from the pretreatment values was observed 30 minutes after treatment and ranged from 32.3 to $56.1 \%$ in study 1 , and from 16.9 to $42.1 \%$ in study 2 . (fig 1). Throughout the entire study period, the greatest decrease in Rrs was observed after aerosol delivery by the ultrasonic nebuliser.

Table 5 Respiratory system resistance before and after salbutamol aerosol

\begin{tabular}{|c|c|c|c|c|c|c|}
\hline \multirow[b]{2}{*}{ Device used } & \multicolumn{6}{|c|}{ Respiratory system resistance $\left(\mathrm{cm} \mathrm{H}_{2} \mathrm{O} / \mathrm{ml} / \mathrm{s}\right):$ mean (SEM) } \\
\hline & Before & $15 \mathrm{~min}$ & $30 \mathrm{~min}$ & $60 \mathrm{~min}$ & $120 \mathrm{~min}$ & $p^{*}$ \\
\hline \multicolumn{7}{|l|}{ Study 1: } \\
\hline 1 (MDI) & $0.339(0.065)$ & $0.229(0.044)$ & $0.175(0.032)$ & $0.225(0.042)$ & $0.278(0.054)$ & $<0.0001 \dagger$ \\
\hline 2 (Jet) & $0.349(0.070)$ & $0.262(0.046)$ & $0.226(0.042)$ & $0.284(0.051)$ & $0.331(0.063)$ & $<0.0001+\dagger$ \\
\hline 3 (Ultrasonic) & $0.369(0.072)$ & $0.202(0.034)$ & $0.146(0.022)$ & $0.219(0.043)$ & $0.298(0.059)$ & $<0.0001^{\star \star}$ \\
\hline \multicolumn{7}{|l|}{ Study 2: } \\
\hline 1 (MDI) & $0.404(0.052)$ & $0.325(0.041)$ & $0.287(0.037)$ & $0.336(0.041)$ & $0.374(0.048)$ & $<0.0001 \dagger$ \\
\hline 2 (Jet) & $0.411(0.057)$ & $0.373(0.052)$ & $0.345(0.050)$ & $0.371(0.051)$ & $0.412(0.054)$ & $<0.0001 \dagger$ \\
\hline 3 (Ultrasonic) & $0.428(0.062)$ & $0.325(0.047)$ & $0.246(0.035)$ & $0.299(0.040)$ & $0.365(0.047)$ & $<0.0001 \dagger$ \\
\hline
\end{tabular}

*One way repeated measures ANOVA.

Multiple pairwise comparison by Student-Newman-Keul Method $(\mathrm{p}<0.05)$ :

†30 min $<15 \mathrm{~min}<60 \mathrm{~min}<120 \mathrm{~min}$ and before treatment;

††30 $\mathrm{min}<60 \mathrm{~min}<120 \mathrm{~min}$ and before treatment, $15 \mathrm{~min}<120 \mathrm{~min}<$ before treatment;

$\star \star 30 \mathrm{~min}<15$ and $60 \mathrm{~min}<120 \mathrm{~min}<$ before treatment. 

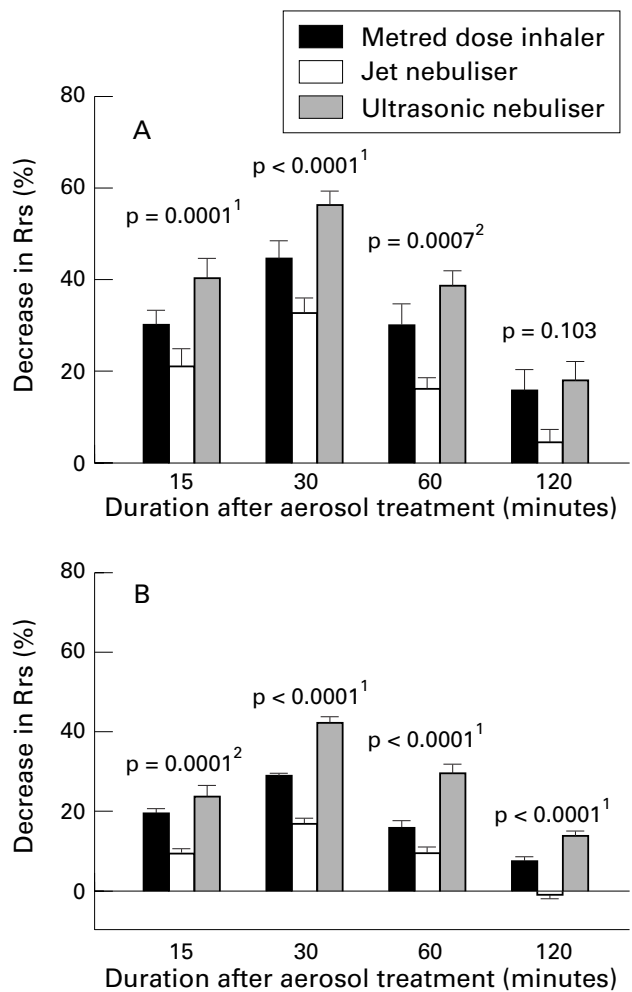

Figure 1 Mean (SEM) percentage decrease in Rrs from pre-treatment values at 15,30, 60 and 120 minutes after administration of salbutamol aerosol using the three types of delivery devices in $(A)$ study 1 and $(B)$ study 2 . One way repeated measures ANOVA showed significant differences among the devices at all time points in both studies except at 120 minutes in study 1. Results of multiple pairwise comparison by the Student-Newman-Keul method are: ${ }^{1} U S>M D I>j e t$, and ${ }^{2} U S$ and $M D I>j e t(p<0.05)$.

The use of the jet nebulisers was, in contrast, associated with the smallest degree of improvement.

\section{Discussion}

The therapeutic effects of aerosolised medications in neonates and small infants are less consistent than those in older children and adults because of the small and variable amount of aerosols that can reach the lungs. ${ }^{23}$ Pulmonary deposition is particularly small in ventilated infants due to loss of aerosol to the ventilator circuit and endotracheal tube. ${ }^{17} 20$ For these infants therapeutic aerosols should be delivered by the most efficient method to achieve the maximum therapeutic effects. Among the delivery devices currently available, the MDI and the jet nebuliser have been compared in two recent studies for their efficiency in delivering salbutamol to preterm infants with chronic lung disease. Using radiolabelled salbutamol, one study showed that pulmonary deposition in ventilated infants was greater from the MDI, although deposition from both devices was small and variable. ${ }^{10}$ The other study showed in spontaneously breathing infants that $200 \mu \mathrm{g}$ of salbutamol delivered by the MDI and spacer reduced dynamic lung resistance as effectively as $600 \mu \mathrm{g}$ delivered by the jet nebuliser. ${ }^{18}$ There is relatively little information on the use of the ultrasonic nebuliser on small infants. Two earlier studies have reported that pulmonary deposition from this device was small and similar to that from the jet nebuliser. ${ }^{913}$ In a study in ventilated adult filter models, however, the device was able to achieve substantial deposition when used together with a large volume fill of $18 \mathrm{ml}$. With a small volume fill $(3 \mathrm{ml})$, pulmonary deposition was small, being comparable with that from the jet nebuliser. ${ }^{19}$ In a recent study on ventilated rabbits, aerosol delivery from the ultrasonic nebuliser was significantly enhanced by nebulising the medication from a small volume medication cup similar to the one used in this study. The use of the small cup resulted in pulmonary deposition more than three times that from the standard reservoir, and more than five times that delivered by the MDI or jet nebuliser. ${ }^{20}$ The conical shape of the small cup provides smaller "dead volume," and more complete aerosolisation of its contents. The complete immersion of the medication inside the coupling fluid might also permit a better interface between the two solutions, resulting in better transmission of vibration energy and higher aerosol output.

Our findings show that salbutamol aerosol administered by all three devices can relieve airway obstruction, resulting in a decrease in Rrs. Maximum improvement was documented 30 minutes after completion of aerosol delivery, and the bronchodilating effect lasted for about 2 hours. Our findings also confirmed the superiority of the MDI spacer to the jet nebuliser. The decrease in Rrs was, however, greatest when the aerosol was delivered using the ultrasonic nebuliser. The maximum percentage drop in Rrs observed at 30 minutes after ultrasonic nebulisation was 1.7 and 2.5 times that associated with the use of the Sidestream and Hudson jet nebulisers, respectively. As the bronchodilating effect of salbutamol is dose dependent, ${ }^{24}$ these findings strongly suggest that among the three types of devices tested, the ultrasonic nebuliser delivered the greatest amount of aerosol to the infants' lungs. Also in support of this were the faster heart rate and the significantly greater though variable increase in $\mathrm{tcpO}_{2}$ and reduction in $\mathrm{tcpCO}$ during the first hour of aerosol delivery by the ultrasonic nebuliser. The mass median aerodynamic diameter (MMAD) of salbutamol aerosol generated by all the devices tested in this study has been estimated before (mean (SEM) MMAD at exit from endotracheal tube: MDI plus MV15 Aerochamber: 1.84 (0.03) $\mu \mathrm{m}$; Sidestream nebuliser: $1.01(0.04) \mu \mathrm{m}$; Hudson jet nebuliser: $0.67(0.07) \mu \mathrm{m}$; Siemens ultrasonic nebuliser with small cup: 1.19 (0.01) $\mu \mathrm{m}) .{ }^{1020}$ Aerosol particles generated by the ultrasonic nebuliser, though larger than those from the jet nebulisers, have sizes well within the respirable range of 1 to $5 \mu \mathrm{m}$. It is therefore unlikely that their greater pharmacological effects have been caused by systemic absorption of a greater amount of impacted salbutamol at the conducting airway.

Unlike Rrs, improvement in Crs was observed only in infants in study 2 following the use of the ultrasonic nebuliser. Improvement in Crs following relief of bronchial constriction is likely to be caused by recruitment of the 
atelectatic alveoli and is often less predictable than a reduction in Rrs. Most of the infants in this study had only mild chronic lung changes requiring only minimal oxygen supplementation. They might not have had extensive lung atelectasis secondary to airway obstruction, and therefore did not show any significant improvement in Crs after bronchodilator treatment.

Our study has provided the first direct comparison of the use of the MDI, the jet nebuliser, and the ultrasonic nebuliser-small cup device in ventilated small infants. Like those of most similar studies, however, our findings are limited to the devices tested and might not be applicable to devices of different makes. Some of the experimental manoeuvres might also lead to bias in favour of the MDI. A uniform nominal dose $(200 \mu \mathrm{g})$ of salbutamol was used with all the devices, but in reality, larger doses of the medication are often used with nebuliser solutions. In accordance with our usual nursery practice, the nebulisers were connected to the ventilator tubing $20 \mathrm{~cm}$ away from the endotracheal tube, and this might have resulted in greater aerosol loss due to impaction. Another limitation is due to the time required for aerosol administration, which was 2 minutes for the MDI, and 13 to 15 minutes for the nebulisers. Thus the aerosol delivered by the nebulisers had a longer time to act on the lungs than that from the MDI before lung mechanics were measured. All these potential biases, however, did not affect the comparison between the ultrasonic and the jet nebulisers. Despite its limitations, our study has provided clinical data which are consistent with the animal deposition study comparing the same devices, ${ }^{20}$ and suggest that the ultrasonic nebuliser-small cup device is superior to the jet nebuliser, and might also be an acceptable alternative to the MDI in the delivery of salbutamol aerosol to ventilated infants.

We thank Mr Eric MC Wong, Centre of Clinical Trial and Epidemiological Research, The Chinese University of Hong Kong, for his statistical assistance.

1 Wilkie RA, Bryan MH. Effect of bronchodilators on airway lung disease. F Pediatr 1987;111:278-82.

2 Motoyama EK, Fort MD, Klesh KW, Mutich RL, Guthrie RD. Early onset airway reactivity in premature infants with bronchopulmonary dysplasia. Am Rev Respir Dis 1987; 136:50-7.

3 Rotschild A, Solimano A, Puterman M, Smyth J, Sharma A, Albersheim S. Increased compliance in response to salbutamol in premature infants with developing bronchopulmonary dysplasia. F Pediatr 1989;115:984-91.

4 Brundage KL, Mohsini KG, Froese AB, Fisher JT. Bronchodilator response to ipratropium bromide in infants with bronchopulmonary dysplasia. Am Rev Respir Dis 1990;142:1137-42.

5 Pfenninger J, Aebi C. Respiratory response to salbutamol (albuterol) in ventilator-dependent infants with chronic lung disease: pressurized aerosol delivery versus intravenous injection. Intensive Care Med 1993;19:251-5.

6 Lee H, Arnon S, Silverman M. Bronchodilator aerosol administered by metered dose inhaler and spacer in subacute neonatal respiratory distress syndrome. Arch Dis Child 1994;70:F218-22.

7 Yuksel B, Greenough A. Effect of nebulized salbutamol in preterm infants during the first year of life. Eur Respir $\mathcal{F}$ 1991;4:1088-92.

8 Watterberg KL, Clark AR, Kelly HW, Murphy S. Delivery of aerosolized medication to intubated babies. Pediatr Pulmonol 1991;10:136-41.

9 Grigg J, Arnon S, Jones T, Clarke A, Silverman M. Delivery of therapeutic aerosols to intubated infants. Arch Dis Child 1992;67:25-30.

10 Fok TF, Dolovich M, Gray S, et al. Efficiency of aerosol medication delivery from a metered dose inhaler versus jet nebuliser in infants with bronchopulmonary dysplasia. Pediatr Pulmonol 1996;21:301-9.

11 Flavin $M$, MacDonald $M$, Dolovich $M$, Coates G, O'Brodovich $\mathrm{H}$. Aerosol delivery to the rabbit lung with an infant ventilator. Pediatr Pulmonol 1986;2:35-9.

12 Cameron D, Arnot R, Clay M, Silverman M. Aerosol delivery in neonatal ventilator circuits: a rabbit lung model. Pediatr Pulmonol 1991;10:208-13.

13 Cameron D, Clay M, Silverman M. Evaluation of nebulizers for use in neonatal ventilator circuits. Crit Care Med 1990;18:866-70.

14 Rozycki HJ, Bryon PR, Dailey K, Gutcher GR. Evaluation of a system for the delivery of inhaled beclomethasone
dipropionate to intubated neonates. Pediatrics 1994; 81:607-706.

15 Arnon S, Grigg J, Nikander K, Silverman M. Delivery of micronized budesonide suspension by metered dose inhaler and jet nebulizer into neonatal ventilator circuit. Pediatr Pulmonol 1992;13:172-5.

16 Everard ML, Stammers J, Hardy JG, Milner AD. New aerosol delivery system for neonatal ventilator circuits. Arch Dis Child 1992;67:826-30

17 O'Callaghan C, Hardy J, Stammers J, Stephenson TJ, Hull D. Evaluation of techniques for delivery of steroids to lungs of neonates using a rabbit model. Arch Dis Child 1992; 67:20-4.

18 Gappa M, Grtner M, Poets CF, von der Hardt H. Effects of salbutamol delivery from a metered dose inhaler versus jet nebulizer on dynamic lung mechanics in very preterm infants with chronic lung disease. Pediatr Pulmonol 1997;23:442-8.

19 Thomas SHL, O'Doherty MJ, Page CJ, Treacher DF, Nunan TO. Delivery of ultrasonic nebulized aerosols to a lung model during mechanical ventilation. Am Rev Respir Dis $1993 ; 148: 872-7$

20 Fok T, Al-Essa M, Monkman S, Dolovich M, Coates G, Bowen B, Kirpalani H. Pulmonary deposition of salbutamol aerosol delivered by metered dose inhaler, jet nebulizer and ultrasonic nebulizer in mechanically ventilated rabbits. Pediatr Res 1997;42:721-7.

21 Northway WH, Rosan RC, Peter DY. Pulmonary disease following respiratory therapy of hyaline-membrane disease. Bronchopulmonary dysplasia. N Engl F Med 1967; 276:357-68.

22 LeSouef PN, England SJ, Bryan AC. Passive respiratory mechanics in newborns and children. Am Rev Respir Dis 1984;129:552-6.

23 Silverman M. Aerosol therapy in the newborn. Arch Dis Child 1990;65:906-8.

24 Denjean A, Guimaraes H, Migdal M, Miramand JL, Dehan $M$, Gaultier C. Dose-related bronchodilator response to aerosolized salbutamol (albuterol) in ventilator-dependent premature infants. F Pediatr 1992;120:974-9. 